\title{
Optical Methods for Estimating Apparent Density of Sediment in Suspension
}

\author{
Alexander J. Hurley ${ }^{1 *}$, Paul S. Hill ${ }^{1}$, Timothy G. Milligan², and Brent A. Law ${ }^{2}$
}

\begin{abstract}
In most aquatic environments, suspended sediment is composed of loosely packed particle aggregates, termed flocs that have variable apparent densities. The apparent density of flocs, which is defined as particle dry mass over wet volume, is an important variable because it affects settling velocity and vertical sediment flux. Two established methods exist for measuring apparent density. One method uses physical measurements of sediment mass concentration combined with measurements of particle volume concentration from optical instruments to estimate apparent density. This method is laborious because it requires the collection of water samples, so it is not conducive to construction of high-resolution time series of density. Another method uses video observations of particles in a settling column to measure particle size and settling velocity. These measurements are used to solve for apparent density according to Stokes Law. The goal of this study is to develop a new method that uses the ratio of particulate beam attenuation to particle volume to estimate apparent density of sediment in suspension. Data from five studies are used to compare density estimates with the new method to the previous methods. The new optical method produces apparent densities that are correlated linearly with measurements of the ratio of dry mass to wet volume. However, the new optical method produces density estimates that do not correlate with video estimates of apparent density. This lack of correlation is due to sampling bias of the video method, which has a relatively large lower limit of resolution in particle size. Development of a higher resolution camera would eliminate the current bias in particle size and would enable further assessment of the new optical method as an accurate proxy for apparent density.
\end{abstract}

Keywords: apparent density; floc; flocculation; LISST; optics; sediment density; sediment deposition; sediment in suspension 
${ }^{*}$ Corresponding author.

E-mail address: alex.hurley@dal.ca (A.J. Hurley); paul.hill@dal.ca (P.S. Hill); Tim.Milligan@dfompo.gc.ca (T.G. Milligan); Brent.Law@dfo-mpo.gc.ca (B.A. Law)

${ }^{1}$ Department of Oceanography, Dalhousie University, Halifax, NS, B3H 4R2, Canada

${ }^{2}$ Fisheries and Oceans Canada, Bedford Institute of Oceanography, Dartmouth, NS, B2Y 4A2, Canada 


\subsection{Introduction}

Small sediment particles in marine environments are often flocculated, which means that small particles are aggregated into larger, composite particles, known as flocs [McCave, 1984; Hill et al., 2011]. Measuring floc properties is difficult because flocs are fragile and easily altered during sampling due to increased fluid shear caused by sampling procedures [Winterwerp and van Kesteren, 2004]. As a consequence, measurements must be carried out in situ and non-invasively in order to preserve natural particle size and apparent density.

Apparent density of particles in a suspension is the total dry mass concentration of particles divided by the total wet volume concentration of the particles. Apparent density affects average particle settling velocity, which is a fundamental variable for determining the vertical flux of sediment in suspension. Due to the variety of mechanisms and associated frequencies driving sediment transport [e.g., Ogston and Sternberg., 1999], long, highresolution time series of apparent density are required to provide a better understanding of the variables that determine this parameter.

Two general methods have been applied to the estimation of apparent density. One method relies on collection and filtration of a known volume of water to estimate suspended particulate dry mass concentration (SPM, see Table 1 for notation) combined with particle sizing instruments to estimate particle volume concentration [e.g., Mikkelsen and Pejrup., 2000]. The other method employs video imaging of settling particles to generate size versus settling velocity relationships that are used to reconstruct particle densities [e.g. Hill et al., 1998; Sternberg et al., 1999; Mikkelsen et al., 2004; Curran et al., 2007].

With these methods it is difficult to construct high-resolution time series of apparent density. Estimation of particle dry mass via collection and filtration of water is laborious, imposing limits on the number of estimates of apparent density that can be generated. Video techniques involve the isolation of a water parcel for fixed periods, again limiting the temporal resolution of density estimates. Limited temporal resolution hampers the development of predictive models of apparent density. 
The primary goal of this research is to explore a new method for estimating apparent density that uses in situ optical instruments. This method uses a Sequoia Scientific LISST 100x laser particle sizer (LISST) and a digital floc camera (DFC) to estimate particle volume concentration and measure particle beam attenuation. The particle beam attenuation is proportional to suspended particle mass concentration [Snyder et al., 2008; Boss et al., 2009b; Neukermans et al., 2012]. With this knowledge, the assumption can be made that the ratio of beam attenuation to particle volume concentration is proportional to apparent density. Apparent densities obtained using the new method are compared to those derived with the two established methods. The secondary goal of this research is to characterize the correlation between observed apparent density and the ratio of particle beam attenuation to particle volume measured with the LISST alone. The LISST particle volume concentration is less than or equal to the total particle volume concentration measured by the LISST and DFC, but if the two estimates of volumes are proportional, then the optical apparent density estimates generated with the LISST alone will be correlated with the more conventional estimates of apparent density (Hill et al., 2013).

\subsection{Materials and Methods}

\subsection{Overview}

Five complete data sets from various sites around North America were analyzed. The term "complete" describes a data set for which data were collected from all of the instruments required for the methods presented in this research. In addition, two data sets were analyzed that did not contain SPM data. Data collection sites covered a range of nearshore environments and included wave-stirred coastal environments, tidally dominated environments, and aquaculture sites (Table 2).

The instrument platform for collection of the majority of the data sets was the Modified In Situ Size and Settling Column Tripod (MINSSECT). The MINSSECT was equipped with a Sequoia Scientific LISST 100x (Type B or Type C) laser particle sizer, a Digital Floc Camera (DFC), a Water Transfer System (WTS, McLane Research Laboratories, Inc. Phytoplankton Sampler) and a Digital Video Camera (DVC) for settling velocity measurements [Hill et al., 2011]. 
MINNSECT was deployed at each location for variable periods. For the RIVET 1 experiment, the DVC was placed on the bottom in a small frame, while the LISST and DFC were mounted on a package that was profiled through the water column. On the tidal flats in Willapa Bay, data were collected with the instruments mounted on small independent frames. The WTS was not deployed during these two experiments.

Suspended particulate mass (SPM) was determined from filters gathered with the WTS and sediment volume concentrations were measured with the LISST and DFC. The DVC recorded video clips of sinking particles in the settling column. From these clips, size-settling velocity data were extracted and used to solve for apparent density [Mikkelsen et al., 2004; Curran et al., 2007]. A new optical method uses data only from the LISST and DFC. Apparent density was estimated using beam attenuation as a proxy for mass, and volume concentration from the size distributions generated by the LISST and DFC.

\subsection{SPM Method}

The SPM method for estimating apparent density makes use of physical measurements of SPM as well as volume measurements from an instrument such as a LISST. Physical SPM measurements require filtration, drying and weighing in the laboratory. Using the dried SPM samples and volume estimates from an optical instrument, apparent density (the ratio of dry weight to wet volume of particles) can be calculated [Mikkelsen and Pejrup., 2000; Babin et al., 2003]:

$$
\left(\rho_{f}-\rho_{w}\right) \propto \frac{S P M}{V_{t}}
$$

The left hand side of Equation 1 is the density of particles in excess of the density of water. This quantity is also referred to as the effective density $\left(\rho_{e}, \mathrm{~kg} \mathrm{~m}^{-3}\right)$, where $\rho_{f}$ is floc density and $\rho_{w}$ is water density (both in $\mathrm{kg} \mathrm{m}^{-3}$ ). The right hand side of the equation is the apparent density ( $\rho_{a}$, 
$\left.\mathrm{kg} \mathrm{m}^{-3}\right)$, where SPM is the dry weight of sediment per unit of fluid volume $\left(\mathrm{kg} \mathrm{m}^{-3}\right)$, and $V_{t}$ is the total volume concentration of suspended particles $\left(\mathrm{m}^{3} \mathrm{~m}^{-3}\right)$.

The effective density $\left(\rho_{e}\right)$ is proportional to the apparent density $\left(\rho_{a}\right)$ as shown in Equation 1. To understand the proportionality, Mikkelsen and Pejrup. [2001] derived an expression for $\rho_{f}$ :

$$
\rho_{f}=\frac{M_{w}+S P M}{V_{t}}
$$

where $M_{w}$ is the mass of water within flocs $(\mathrm{kg})$. Assuming that flocs are composed of only water and the component solid particles, $M_{w}$ can be expanded to give the following:

$$
M_{w}=\rho_{w}\left(V_{t}-V_{s}\right)
$$

The relationship between SPM, sediment density $\left(\rho_{s}, \mathrm{~kg} \mathrm{~m}^{-3}\right)$ and sediment volume $\left(V_{s}, \mathrm{~m}^{3} \mathrm{~m}^{-3}\right)$ can be described by the following:

$$
S P M=\rho_{s} * V_{s}
$$

By substituting Equation 2 into Equation 3 one can solve for $\rho_{f}$ :

$$
\rho_{f}=\frac{\rho_{w}\left(V_{t}-V_{s}\right)+\rho_{s} V_{s}}{V_{t}}=\rho_{w}+\left(\rho_{s}-\rho_{w}\right)\left(\frac{V_{s}}{V_{t}}\right) .
$$

By subtracting $\rho_{w}$ from each side of Equation 4 and multiplying the resulting right hand side by $\left(\rho_{s} / \rho_{s}\right)$, an alternate expression for effective density results:

$$
\rho_{e}=\rho_{f}-\rho_{w}=\frac{\left(\rho_{s}-\rho_{w}\right)}{\rho_{s}}\left(\frac{\rho_{s} V_{s}}{V_{t}}\right) .
$$


With rearrangement of Equation 5 to solve for effective density, the proportionality of effective density to apparent density can be calculated:

$$
\begin{gathered}
\rho_{e}=\left(\frac{\rho_{s}-\rho_{w}}{\rho_{s}}\right) \rho_{a} . \\
\rho_{a}=\left(\frac{\rho_{s}}{\rho_{s}-\rho_{w}}\right) \rho_{e} .
\end{gathered}
$$

In Equations 6 and $7 \rho_{s}$ is the particle density of the component particles that constitute the flocs. A value of $2650 \mathrm{~kg} \mathrm{~m}^{-3}$ (density of quartz) is commonly used.

\subsection{DVC Method}

The DVC method uses a digital video camera (DVC) to measure settling velocity and particle diameter. The DVC is mounted to a settling column with a mechanized lid that closes at specified intervals. The height of the settling column is $51 \mathrm{~cm}$, while the opening of the column is $10 \times 4 \mathrm{~cm}$. When the lid of the column is open, suspended sediment sinks into it, and the DVC does not record. When the lid closes, the camera begins to record video after 15 seconds. The lag between closing time and start time allows flow-induced turbulence in the column to dissipate. In addition to the mechanized lid, the opening of the settling column is equipped with a baffled top. The mechanized lid and baffled top assist in minimizing the flow disruptions of settling particles within the column. The DVC records video on 80-min mini Digital Video (miniDV) tapes. During video capture, the DVC records 1-minute video clips.

The recovered miniDV tapes are processed in the laboratory. Video editing software (Sony Imageshaker) is used to separate and create digital copies of each recorded clip [Mikkelsen et al., 2004]. The 1-minute digital clips are loaded one at a time and examined for 
the presence of settling particles or any irregularities, such as upward or oscillating particle trajectories, which indicate inadequate isolation of the settling column from the surrounding environment. After observation, the user chooses a 4-second section in the video that is identified as representative of the particles in the entire video. From the 4-second section, four frames are captured, with a 1-second spacing. A final frame is captured at the end of the clip for the purpose of subtracting any stationary objects in the windows of the DVC. The five images are converted to binary images, using a greyscale threshold to identify particle edges [Fox et al., 2004; Mikkelsen et al., 2004]. Otsu's method [Otsu, 1979] is used to generate the initial threshold values for a set of images, but the threshold can be adjusted by the user if the particle outlines in the binary images are not similar in shape or size to the original images. Particles in each image are numbered and tagged sequentially. Particle tags are placed into the image, with a different colour for each image. The four tagged images are combined, and tracks are recorded by entering the colour-coded numbers in a text file. A minimum of three particle appearances in a particle track is required for analysis. The text file containing the particle tags for each track is used to extract nominal diameter, settling time, settling distance and settling velocity [Fox et al., 2004; Hill et al., 2011].

Stokes Law is used to estimate effective density for each particle (Equation 8):

$$
\left(\rho_{f}-\rho_{w}\right)=\left(\frac{W_{s} * 18 \mu}{g * D^{2}}\right)
$$

The variable $W_{s}$ is the settling velocity $(\mathrm{m} / \mathrm{s}), \mu$ is the dynamic viscosity $\left(\mathrm{kg}(\mathrm{m} \mathrm{s})^{-1}\right), g$ is acceleration due to gravity $\left(9.8 \mathrm{~m} \mathrm{~s}^{-2}\right)$, and $D$ is the equivalent circular diameter of the particle (m). The dynamic viscosity was calculated using a global temperature and salinity of $10{ }^{\circ} \mathrm{C}$ and 25 PSU respectively. The left hand side of the equation is equal to $\rho_{e}$. If Equation 8 is substituted into Equation 7, then apparent density can be calculated: 


$$
\rho_{a}=\left(\frac{W_{s} * 18 \mu}{g * D^{2}}\right)\left(\frac{\rho_{s}}{\rho_{s}-\rho_{w}}\right) .
$$

For this equation, a value of $2650 \mathrm{~kg} \mathrm{~m}^{-3}$ (density of quartz) is used for $\rho_{s}$. The assumption that the apparent densities in Equations 1 and 9 are equal will be true if the sizes of sediment in suspension lie within the resolution limits of the DVC, where the minimum resolvable particle diameter is $180 \mu \mathrm{m}$ [Mikkelsen et al., 2004].

\section{$2.4 \quad$ LD Method}

The proposed optical proxy for apparent density is referred to as the $L D$ method, because it uses a LISST and DFC combination to estimate particle dry mass and wet volume concentrations. Together, these instruments resolve a particle diameter range of $1.25 \mu \mathrm{m}$ to 4 $\mathrm{cm}$ for LISST B and $2.50 \mu \mathrm{m}$ to $4 \mathrm{~cm}$ for LISST C [Hill et al., 2011]. The LISST, an instrument from Sequoia Scientific, measures beam attenuation $\left(c_{p}, \mathrm{~m}^{-1}\right)$ and estimates particle volume concentrations over particle diameters ranging from 1.25 to $250 \mu \mathrm{m}$ for type $B$ and 2.5 to 500 um for type C [Mikkelsen et al., 2005; Hill et al., 2011; Neukermans et al., 2012]. Software from Sequoia Scientific is used to invert the scattered light measurements to determine particle size distribution and to calculate the beam attenuation coefficient. The spherical shape matrix was used to invert the archived Oasis 2007 and Willapa data sets. The random shape matrix was used to process the other data sets. To calculate the $c_{p}$, the software calculates the ratio of the transmitted light intensity to the transmitted light intensity in particle-free water [Mikkelsen et al., 2005; Hill et al., 2011]. This method accounts for attenuation due to water. The light transmitted by the LISST has a wavelength of $670 \mathrm{~nm}$, which reduces light attenuation from dissolved substances. Assuming that attenuation due to water and attenuation due to dissolved substances have been addressed, the total beam attenuation coefficient can be used as an estimate of the particulate beam attenuation coefficient.

The DFC measures particles with diameters that range from $45 \mu \mathrm{m}$ to $4 \mathrm{~cm}$. It captures images of suspended particles with silhouette photography at identical time intervals as the 
LISST. These images are captured as water flows through $2.5 \mathrm{~cm}$ gap between two glass plates with a sensing zone of approximately $4 \times 4 \mathrm{~cm}$ [Mikkelsen et al., 2004; Mikkelsen et al., 2005; Hill et al., 2011]. After recovery, images are examined for quality, and photos that are not satisfactory are removed. Images that are removed during quality control are those that contain bubbles, long organics, large organics (e.g. fish), and digitally corrupted, incomplete images. After this quality assessment, an area of interest (AOI) is chosen for a single deployment or series of deployments. The AOI is chosen to reduce the amount of stationary debris in the images [Hill et al., 2011]. Software written in Matlab takes the acceptable colour images, crops them and converts them to grey scale. Variation in background pixel intensity is reduced by applying a top-hat filter to the images. Particles are distinguished from the background using Otsu's method [Otsu, 1979; Hill et al., 2011]. Particle areas are calculated and converted to equivalent spherical volumes and diameters. Stationary debris can be subtracted over a series of images. Average pixel intensities in 6-hour bins are calculated, and pixels that are consistently darker than other pixels are identified as stationary debris on the camera windows and removed from the analysis.

Merging the LISST and DFC data is accomplished by first distributing the equivalent spherical volumes into 57 logarithmic size bins based on diameter. Bin diameters are set by the LISST model used ( $B$ or $C$ ), inversion matrix and are extended to include the size range of the DFC. Specified lower size bins of the DFC are joined with specified upper size bins of the LISST via linear interpolation in log space, producing a merged size distribution that covers particle diameters from $1.25 \mu \mathrm{m}$ to over $4 \mathrm{~cm}$ for LISST B or $2.50 \mu \mathrm{m}$ to over $4 \mathrm{~cm}$ for LISST C.

The LD method assumes that beam attenuation is proportional to mass concentration in suspension (SPM) [Boss et al., 2009b; Hill et al., 2011]. Therefore:

$$
\rho_{a}=\frac{S P M}{V_{t}} \propto \frac{c_{p}}{V_{t}}
$$


To simplify the comparison between the different density estimates, $c_{p}: V_{t}$ ratios (units of $m^{-1}$ ) were multiplied by a generic proportionality coefficient between SPM and $c_{p}$. Numerous studies indicate that $c_{p}: S P M$ ratios are approximately $1 \mathrm{~g} \mathrm{~m}^{-2}$, which can be converted to approximately $10^{-3} \mathrm{~kg} \mathrm{~m}^{-2}$ [cf. Hill et al., 2011]. This value varies due to particle composition [Babin et al., 2003; Hill et al., 2013] and to acceptance angle of the instrument [Boss et al., 2009a]. Composition affects the ratio maximally by a factor of 2 , and only LISSTs were used to measure $c_{p}$ in this study. Values of $c_{p}: V_{t}$, therefore, were multiplied by $10^{-3} \mathrm{~kg} \mathrm{~m}^{-2}$, and the resulting units of the modified $c_{p}: V_{t}$ values are $\mathrm{kg} \mathrm{m}^{-3}$. Alternatively, one could apply a study-specific value of $c_{p}: S P M$ to each data set [e.g. Hill et al., 2011], but given the goal of this study is to examine the robustness of $c_{p}: V_{t}$ as a proxy for density without prior knowledge of this ratio, the application of a single generic proportionality coefficient was deemed the more stringent test of the LD method.

The data collected from the LISST and DFC are summarized in Table 3. There were two modes of deployment for the LISST and DFC packages. The first method of deployment was a stationary deployment, where the LISST, DFC and DVC were all deployed on the same frame and left for a period of time to collect data. The second deployment mechanism was a cast deployment and involved a smaller instrument frame with only the LISST and DFC. In this deployment method, the DVC was deployed and was stationary for a given time period while the LISST/DFC package was profiled repeatedly in the vicinity of the DVC.

The comparison between the DVC method and the LD method is based on sampling time. After the particle tracks are processed, the apparent densities are calculated for all data points. The median of apparent densities is taken for each clip, creating one density for a given sample time. The apparent densities from the LD method are calculated for all merged data size distributions within \pm 5 minutes of the DVC sampling time.

\section{$2.5 \quad C_{p}: V_{\text {LISST }}$}

In addition to densities estimated with the LD method, another estimate of density is based on LISST data alone: 


$$
\rho_{a}=\frac{c_{p}}{V_{\text {LISST }}}
$$

Equation 12 is equivalent to Equation 11 except $V_{t}$ is replaced with $V_{\text {LISST, which is the volume }}$ estimated from the LISST only. This apparent density proxy is included in the method comparison because the LISST is a commercially available, widely used instrument. While it is more accurate to merge LISST and DFC data to span the entire size distribution, the DFC is a custom instrument. Therefore, a density proxy calculated using just LISST data would be more widely available provided the volume measured by the LISST is proportional to the total volume.

\subsection{Suspended Particulate Mass Collection}

This study uses two primary methods to obtain a direct estimate of suspended particulate mass (SPM, $\mathrm{g} \mathrm{m}^{-3}$ ) concentration. The first method uses a McLane Research Laboratories Inc. Phytoplankton Sampler water transfer system (WTS) to directly estimate SPM. The SPM is obtained from 24 filters held by the WTS. At regular intervals, a specified volume of sediment-laden water is passed through a filter. The filters used are pre-weighed Millipore 8.0

$\mu \mathrm{m}$ SCWP (cellulose acetate). These were selected on the basis of small operational pore sizes and reduced clogging [Hill et al., 2011]. The second method for measuring SPM involves the collection water samples using Niskin bottles. The SPM samples retrieved from Niskin bottles were collected at the same depth and location of the instrument package containing the LISST, DFC and DVC. After filtration, the pre-weighed, sediment-laden filters are rinsed thoroughly with super $Q$ water, dried in an oven at $50{ }^{\circ} \mathrm{C}$, and weighed. Sediment mass is equal to the total filter mass minus the pre-weighed filter mass. SPM is found by dividing the sediment mass by the volume of suspension that is filtered.

\subsection{Data Correction}

During data collection and processing, corrections were necessary for some of the data sets. The data sets that needed to be corrected were those from the Oasis 2011 and Hudson 
experiments. During the deployments of Oasis 2011, barnacle growth was observed on the instruments of MINSSECT. This growth affected the $c_{p}$ and volume concentration data collected by the LISST and DFC. Barnacle growth produced artificially high particulate beam attenuation coefficients and volume concentrations, which increased exponentially during the deployment. To correct for this with the LISST data, an exponential fit was applied to the attenuation data, and then subtracted from the data. For the DFC data, the effect of barnacles was removed via the background subtraction process outlined previously in section 2.3. This background subtraction lowers volume concentrations, as the barnacles mask the presence of any particles in the portions of the images covered by barnacles, but areal coverages of barnacles made up only a few percent or less of the total field of view. It should be noted that for the LISST volume concentration data, only bins 27 to 32 of the 32 LISST size bins were affected by barnacle fouling, and these bins are not used in the merged particle size distributions.

During the Hudson experiment, negative $c_{p}$ values were observed. Although the LISST is calibrated for clear water (section 2.3), the particulate beam attenuation coefficients recorded by the LISST during this experiment were lower than that of the calibration. To correct for this, a new clear water transmission value was taken as the highest transmission value for the deployment. The new clear water value of transmission was then used to recalculate beam attenuation coefficients.

\subsection{Results}

\subsection{Overview}

In this study, data were collected in a variety of nearshore environments, with a range of weather forcing. This variety resulted in variable particles sizes, settling velocities and water conditions. The range in conditions allows for a reasonable assessment of the validity of the LD method as an alternative for the established methods (DVC method and SPM method). Comparison of the LD method against the established methods yields conflicting results.

\subsection{SPM Method}


A summary of the data collected using this method is contained in Table 4. In total, 377 SPM samples were collected across all of the included experiments in Table 4. Median SPM values range from $2.67 \mathrm{~g} \mathrm{~m}^{-3}$ to $6.25 \mathrm{~g} \mathrm{~m}^{-3}$, while median apparent densities ranged from $24 \mathrm{~kg}$ $\mathrm{m}^{-3}$ to $360 \mathrm{~kg} \mathrm{~m}^{-3}$. It is helpful to recall that apparent densities are equal to the dry mass concentration divided by the wet volume concentrations, so the largest flocs, which can have solid volumes that are much smaller than their water volumes, have apparent densities that are close to 0 .

\subsection{DVC Method}

The number of particles tracked in a given experiment is affected by the presence of particles (i.e. lower sediment concentration means fewer particles tracked), number of deployments, and recoverable data. A total of 21923 particles were tracked in this research across different depositional environments, and similarities can be observed among the individual experiments. Median settling velocities range from $0.81 \mathrm{~mm} \mathrm{~s}^{-1}$ to $1.13 \mathrm{~mm} \mathrm{~s}^{-1}$, while median particle diameters range from $300 \mu \mathrm{m}$ to $400 \mu \mathrm{m}$. Median apparent densities range from $26 \mathrm{~kg} \mathrm{~m}^{-3}$ to $45 \mathrm{~kg} \mathrm{~m}^{-3}$. Unlike the relatively large range and values of the median apparent densities from the SPM method, the range and median values using the DVC method are significantly smaller. This observation suggests that the DVC is biased to larger particle aggregates, which decrease in density with increasing particle size [Hill et al., 1998; Agrawal and Pottsmith, 2000].

\subsection{LD Method}

The merged data (from the LISST and DFC) are summarized in Table 6. The total number of merged data points that were collected throughout all experiments is 29330 . The median diameters (D50) range from $140 \mu \mathrm{m}$ to $300 \mu \mathrm{m}$ and the median apparent densities range from $15 \mathrm{~kg} \mathrm{~m}^{-3}$ to $100 \mathrm{~kg} \mathrm{~m}^{-3}$. When comparing the summarized results to those of the established method, significant differences can be observed. When comparing the median apparent densities from Table 6 to those of Table 5 (DVC method), the DVC, on average, images less dense particles than the LD method. The DVC also records larger particle aggregates. 


\section{5 $\quad C_{p}: V_{\text {LISST }}$}

Median diameters range from $30 \mu \mathrm{m}$ to $350 \mu \mathrm{m}$ and median $\mathrm{c}_{\mathrm{p}}: \mathrm{V}_{\text {LISST }}$ ratios range from $40 \mathrm{~kg} \mathrm{~m}^{-3}$ to $220 \mathrm{~kg} \mathrm{~m}^{-3}$ across 19607 data points. In comparison to the LD method data summary, differences in the range of D50 and median apparent densities are apparent. The data using only the LISST records smaller particles due to the lower size range. This initial comparison suggests that using $c_{p}: V_{\text {LISST }}$ data may not be representative if the particles are larger than the instrument's size range ( $>250 \mu \mathrm{m}$ for LISST B, and > $500 \mu \mathrm{m}$ for LISST C).

\subsection{Method Comparison}

The nonparametric Spearman's rho was used to test for correlation between density estimates. This statistic was used because the Shapiro-Wilk test indicated that the apparent densities estimated using all four methods were neither normally nor lognormally distributed ( $p$ $<0.05)$.

Apparent densities estimated by the DVC method and the LD method are not correlated $(p=0.28)$ (Table 8 and Figure 1). Density estimates from the LD and SPM methods are correlated $(p=0)$ (Table 8). Logarithmic transformation was used to linearize the data while equalizing the variance. A Type II regression was applied to the transformed data. The slope of the regression line is 1.05 , with $95 \%$ confidence intervals of 0.95 and 1.16 . These results indicate that the relationship between the LD method and the SPM method is not significantly different from a linear relationship (Figure 2). Using the same approach, apparent density proxies using $c_{p}: V_{\text {LISST }}$ are correlated with the estimates using the SPM method $(p=0)($ Table 8). The slope of the regression line, however, is 0.74 with $95 \%$ confidence intervals of 0.64 and 0.84 . These results show that while the $c_{p}: V_{\text {LISST }}$ proxy is correlated with the SPM method, the correlation is not linear (Figure 3).

\subsection{Discussion}

\subsection{DVC Method versus LD Method}


Apparent densities estimated using the DVC method and the LD method are not correlated. Lack of correlation between the density estimates likely arises because the DVC, with a lower limit of resolution approximately equal to $180 \mu \mathrm{m}$, is biased toward larger, lower density flocs. This hypothesis can be addressed by examining apparent densities from each method as functions of the median diameter (D50) at the same sampling time in the Parr 1 data set (Figure 4). Median diameters were derived from total merged volume concentrations. Apparent density estimated using the LD method increases with decreasing particle diameter (Figure 4), which is due to the fact that particles in suspension are flocs. As the flocs grow in diameter, the apparent densities decrease [McCave, 1984]. For densities estimated with the DVC, however, no correlation exists between apparent density and median diameter (Figure 4). Lack of correlation indicates that the DVC observes particles with similar apparent density, because the DVC is unable to observe particles smaller than $180 \mu \mathrm{m}$. As a result, the DVC estimates remain relatively constant over a range of median diameters.

\subsection{LD Method versus SPM Method}

The comparison of apparent densities estimated using the LD method versus the apparent densities estimated from the SPM method yielded a linear correlation. The linear correlation indicates the LD method is a reasonable proxy for apparent density. The proportionality between SPM and $c_{p}$ does not vary widely because particles are packaged as aggregates in which area is proportional to mass, and compositional variability only accounts for approximately a factor of 2 variation in the coefficient of proportionality [Babin et al., 2003; Slade et al., 2011; Hill et al., 2011; Hill et al., 2013]. Another way to explain the linear correlation is to recognize that the ratio of $c_{p}$ to volume actually is a proxy for the inverse of the Sauter mean diameter of particles in suspension. The Sauter mean diameter is the diameter of a sphere that has the same surface area to volume ratio of an entire suspension of particles, and it is calculated as the total volume concentration divided by the total area concentration in suspension [Filippa et al., 2012]. Because $c_{p}$ is proportional to particle area concentration, $c_{p}: V_{t}$ is proportional to the inverse of the Sauter mean diameter. For particles packaged as aggregates, density decreases approximately as the inverse of particle diameter [Figure 4; 
McCave, 1984], which therefore makes $c_{p}: V_{t}$ a useful proxy for apparent density. Correlation between the LD method and the DVC method would help to further support the LD method as an accurate apparent density proxy because the measurements used in the DVC method are independent of those used in the LD method.

The proportionality between apparent density estimates from the SPM and LD methods possibly could have been degraded by dependence of the residuals of the Type II regression between beam attenuation and SPM on total particle volume [e.g. Boss et al., 2009b]. To illustrate, suppose that residuals in $c_{p}$ tend to be negative when measured particle volumes are small, and that residuals in $c_{p}$ tend to be positive when measured particle volumes are large. This type of variation would tend to equalize estimates of apparent density from the LD method, possibly destroying correlation between apparent densities estimated with the SPM and LD methods. The observed linear correlation between the two estimates indicates that correlation between the residuals of $c_{p}$ and volume did not degrade the LD method estimates of apparent density significantly.

\section{3 $\quad C_{p}: V_{\text {LISST }}$ versus SPM Method}

The comparison of the apparent density proxy using $c_{p}: V_{\text {LISST }}$ with the apparent density estimates from the SPM method yielded an exponential correlation. This result likely arises due to the limited size ranges of the LISST Type B and Type C. From visual inspection, the relationship between $\mathrm{V}_{\text {LISST }}$ and $\mathrm{V}_{\mathrm{t}}$ is linear for smaller $\mathrm{V}_{\mathrm{t}}$, but at larger $\mathrm{V}_{\mathrm{t}}$, the linear relationship breaks down, yielding an overall concave-down shape to the relationship (Figure 5). Larger $\mathrm{V}_{\mathrm{t}}$ comes primarily from data collected during the Oasis 2011 experiment, where larger particle sizes that have lower densities are predominant (Figure 2 and 3, shaded circles). The larger particles present in Oasis 2011 exceed the size limits of the LISST, so VLISST is an underestimate, yielding densities that are overestimates. The upper size limit of the LISST is well known and previously documented as a potential issue because flocs that are larger than the size restrictions of the LISST can be abundant (Hill et al., 2013, Davies et al., 2012). For much of the data, however, the relationship between $V_{\text {LISST }}$ and $V_{t}$ is approximately linear, indicating that $\mathrm{C}_{\mathrm{p}}: \mathrm{V}_{\text {LISST }}$ is a useful proxy for apparent density. 


\subsection{Example Application: Benthic Nepheloid Layer Dynamics}

Based on the correlation between the apparent densities from the SPM method and LD methods, it is reasonable to use time series of particle size distributions and beam attenuation to construct time series of proxies for apparent density (Figure 6). Time series of the proxies can yield insight into particle dynamics in the bottom boundary layer.

A time series from Oasis 2007 has a large dynamic range in apparent density and $\mathrm{C}_{\mathrm{p}}: \mathrm{V}_{\text {LISST. }}$ For this experiment, shear velocity measurements were made by colleagues at Woods Hole Oceanographic Institution [see Hill et al., 2011]. In Oasis 2007 (Figure 6), around year day 255 and again around year day 258, increases in beam attenuation lagged increases in shear velocity. Beam attenuation increased after the peak in shear velocity. The lag likely arose because there was a limited supply of resuspendable sediment in the seabed. As shear velocity increased, the limited supply of sediment was resuspended and distributed throughout a thick boundary layer, which resulted in lower beam attenuation, initially. As the stress began to decrease, the boundary layer thinned. Sediment sank into this thinner boundary layer but did not deposit immediately because stresses were too high. The net flux of sediment into a thinner boundary layer caused sediment concentration and beam attenuation to increase.

Accompanying the increase in beam attenuation was a decrease in apparent density and $C_{p}: V_{\text {LISST. }}$ A decrease would have occurred if flocculation rate increased in response to larger concentrations, which would have produced larger flocs with lower apparent densities and lower ratios of $c_{p}: V_{\text {LISST }}$. Eventually when stress was low enough, large flocs deposited, leaving only small, relatively dense microflocs and single grains in suspension. These particles had larger apparent densities and larger $\mathrm{c}_{\mathrm{p}}: \mathrm{V}_{\text {LISST }}$ ratios.

\subsection{Recommendations}

The most likely cause for the lack of correlation between the DVC and LD methods is the particle size restrictions of the camera used in the DVC method. Given the restrictions of the video camera, emphasis should be placed on the development of a new camera that is capable of sampling smaller particles more frequently. With a video camera that is capable of imaging particles smaller than the current camera, a comparison between the DVC method and the LD 
method should reveal better correlation between the two estimates of density. This comparison is necessary because although the SPM method and LD method are correlated, the same particle volume concentration is used in both methods. The DVC method, in contrast, uses measurements independent of the LD method.

The LD method does not consider the effect that particle composition has on apparent density. Although the results indicate a robust relationship between $S P M$ and $c_{p}$, a more refined relationship between $c_{p}$ and SPM could improve the optical proxy for apparent density. The $C_{p}: S P M$ ratio is a function of composition and a measurement that accounts for particle composition is backscatter ratio [Twardowski et al., 2001]. When backscatter ratio is high, the flocs are composed mostly of inorganic particles, and when backscatter ratio is low the flocs are mostly composed of organic particles. If particle composition were considered, then variance in the relationship between the optical proxy for density and density from the SPM method could be reduced [Babin et al., 2003; Hill et al., 2013].

\subsection{Conclusions}

In conclusion, the apparent densities estimated using LD method are linearly correlated with those estimated using the SPM method. This result suggests that the LD method can be used as a proxy for apparent density. However, the apparent density estimates using the LD method do not correlate with the independent density estimates from the DVC method. Lack of correlation is due to the relatively larger lower limit resolution of the DVC. Using $C_{p}: V_{\text {LISST }}$ produces a viable proxy for apparent density provided that the bulk of sediment in suspension is within the LISST particle size limits. If particles exceed the size limits of the LISST then the proxy will result in an overestimate of the density of the larger, lower density particles.

Trends in apparent density compare well with trends in shear velocity and beam attenuation and can be used to interpret which processes affect particle properties in the bottom boundary layer. In the Oasis 2007 time series, the offset between beam attenuation and shear velocity likely occurs because there was a limited sediment supply that was suspended throughout a thick boundary layer when shear velocity increased. As shear velocity decreased, the bottom boundary layer collapsed, allowing sediment deposition into the thin 
boundary layer, which resulted in higher sediment concentrations. The lag between beam attenuation and apparent density is interpreted as an increase in flocculation due to the high sediment concentrations. When the large flocs are in suspension, apparent density is low. When the large flocs are deposited, apparent density increases.

Ultimately, development of a new DVC that has the ability to resolve smaller particles would provide more insight into whether the LD method is a suitable replacement for the DVC method. Based on the results presented here, the LD method is a suitable replacement for the SPM method. However, because the variable estimates used in the DVC method are independent of those used in the LD method, correlation between these methods would further validate the LD method as an accurate proxy for apparent density. 


\section{Acknowledgements}

We would like to thank John Newgard and Emmanuel Boss for their expertise and ideas in many aspects of this research. We would also like to thank members of the BIO Particle Dynamics lab for their help in data collection and organization. This project was made possible with the funding from the U.S. Office of Naval Research grants N00014-13-1-0506 and the Natural Sciences and Engineering Research Council in Canada.

\section{References}

Agrawal, Y.C. and H.C. Pottsmith (2000), Instruments for particle size and settling velocity observations in sediment transport, Marine Geology, 168, 89-114.

Babin, M., A. Morel, V. Fournier-Sicre, F. Fell, and D. Stramski (2003), Light scattering properties of marine particles in coastal and open ocean waters as related to the particle mass concentration, Limnology and Oceanography, 48, 843-859.

Boss, E., W.H. Slade, M. Behrenfeld, and G. Dall'Olmo (2009a), Acceptance angle effects on the beam attenuation in the ocean, Optics Express, 17(3), 1535-1550.

Boss, E., L. Taylor, S. Gilbert, K. Gundersen, N. Hawley, C. Janzen, T. Johengen, H. Purcell, C. Robertson, D.W.H. Schar, G.J. Smith, and M.N. Tamburri (2009b), Comparison of inherent optical properties as a surrogate for particulate matter concentration in coastal waters, Limnology and Oceanography: Methods, 7, 803-810.

Curran, K.J., P.S. Hill, T.G. Milligan, O.A. Mikkelsen, B.A. Law, X. Durrieu de Madron, and F. Bourrin (2007), Settling velocity, effective density, and mass composition of suspended sediment in a coastal bottom boundary layer, Gulf of Lions, France, Continental Shelf Research, $27,1408-1421$.

Davies, E.M., W.A.M. Nimmo-Smith, Y.C. Agrawal, and A.J. Souza (2012), LISST-100 response to large particles, Marine Geology, 307-310, 117-122.

Filippa, L., A. Trento, and A.M. Alvarez (2012), Sauter mean diameter determination for the fine fraction of suspended sediments using a LISST-25X diffractometer, Measurement, 45(3), 364368.

Fox, J.M., P.S. Hill, T.G. Milligan, A.S. Ogston, and A. Boldrin (2004), Floc fraction in the waters of the Po River Delta, Continental Shelf Research, 24, 1699-1715. 
Hill, P.S., J.P. Syvitski, E.A. Cowan, and R.D. Powell (1998), In situ observations of floc settling velocities in Glacier Bay, Alaska, Marine Geology, 145(1-2), 85-94.

Hill, P.S., E. Boss, J.P. Newgard, B.A. Law, and T.G. Milligan (2011), Observations of the sensitivity of beam attenuation to particle size in a coastal bottom boundary layer, Journal of Geophysical Research, 116, C02023, 1-14.

Hill, P.S., D.G. Bowers, K.M. Braithwaite (2013), The effect of suspended particle composition on particle area-to-mass ratios in coastal waters, Methods in Oceanography, 7, 95-109.

McCave, I.N. (1984), Size spectra and aggregation of particles in the deep ocean, Deep Sea Research, Part A, 31(4), 329-352.

Mikkelsen, O.A., and M. Pejrup (2000), In situ particle size spectra and density of particle aggregates in a dredging plume, Marine Geology, 170, 443-459.

Mikkelsen, O.A., and M. Pejrup (2001), The use of a LISST-100 laser particle sizer for in-situ estimates of floc size, density and settling velocity, Geo-Marine Letters, 20, 187-195.

Mikkelsen, O. A., T.G. Milligan, P.S. Hill, and D. Moffatt (2004), INNSECT - An instrumented platform for investigating floc properties close to the seabed, Limnology and OceanographyMethods, 2, 226-236.

Mikkelsen, O.A., T.G. Milligan, P.S. Hill, and R.J. Chant (2005), In situ particle size distributions and volume concentrations from a LISST-100 laser particle sizer and a digital floc camera, Continental Shelf Research, 25(16), 1959-1978.

Neukermans, G., H. Loisel, X. Meriaux, R. Astoreca, and D. McKee (2012), In situ variability of mass-specific beam attenuation and backscattering of marine particles with respect to particle size, density, and composition (2012), Limnology and Oceanography, 57(1), 124-144.

Otsu, N. (1979), A threshold selection method from gray-level histograms, IEEE Trans. Syst. Man Cybern., 9(1), 62-66.

Ogston, A.S., and R.W. Sternberg (1999), Sediment-transport events on the northern California continental shelf, Marine Geology, 154, 69-82.

Sternberg, R.W., I. Berhane, and A.S. Ogston (1999), Measurement of size and settling velocity of suspended aggregates on the northern California continental shelf, Marine Geology, 154, 4353.

Slade, W.H., E. Boss, and C. Russo (2011), Effects of particle aggregation and disaggregation on their inherent optical properties, Optics Express, 19(9), 7945-7959. 
Snyder, W.A., R.A. Arnone, C.O. Davis, W. Goode, R.W. Gould, S. Ladner, G. Lamela, W.J. Rhea, R. Stavn, M. Sydor, and A. Weidemann (2008), Optical scattering and backscattering by organic and inorganic particulates in the U.S. coastal waters, Applied Optics, 47(5), 666-677.

Twardowski, M.S., E. Boss, J.B. Macdonald, W.S. Pegau, A.H. Barnard, J. Ronald, and V. Zaneveld (2001), A model for estimating bulk refractive index from the optical backscattering ratio and the implications for understanding particle composition in case I and case II waters, Journal of Geophysical Research, 106, 14129-14142.

Winterwerp, J.C., and W.G.M. van Kesteren (2004), Introduction to the physics of cohesive sediment in the marine environment, Developments in Sedimentology, 56, 466. 


\begin{tabular}{|c|c|}
\hline Symbol & Parameter Definition and Units \\
\hline$c_{p}$ & Beam Attenuation $\left(\mathrm{m}^{-1}\right)$ \\
\hline$c_{p}: S P M$ ratio & Beam Attenuation to SPM conversion $\left(\mathrm{m}^{2} \mathrm{~g}^{-1}\right)$ \\
\hline D50 & Median Particle Diameter $(\mu \mathrm{m})$ \\
\hline$D$ & Elliptical Nominal Diameter ( $\mu \mathrm{m}$ converted to $\mathrm{m}$ ) \\
\hline DFC & Digital Floc Camera \\
\hline DVC & Digital Video Camera \\
\hline DVC method & $\begin{array}{l}\text { Established method for calculating apparent density of sediment } \\
\text { in suspension. Requires size-settling velocity data from the DVC. }\end{array}$ \\
\hline$g$ & Gravitational acceleration $\left(\mathrm{m} \mathrm{s}^{-2}\right)$ \\
\hline LD method & $\begin{array}{l}\text { LISST-DFC method for calculating apparent density of sediment in } \\
\text { suspension. Requires only optics. }\end{array}$ \\
\hline LISST & Sequoia Scientific LISST 100x laser particle sizer (Type B or Type C) \\
\hline MINSSECT & Modified in Situ Size Settling Column Tripod \\
\hline$M_{s}$ & Suspended Particulate Mass $\left(\mathrm{g} \mathrm{m}^{-3}\right)$ \\
\hline$M_{w}$ & Mass of Seawater in flocs $\left(\mathrm{g} \mathrm{m}^{-3}\right)$ \\
\hline SPM method & $\begin{array}{l}\text { Established method for calculating apparent density of sediment } \\
\text { in suspension. Requires collection of water. }\end{array}$ \\
\hline$V_{s}$ & Volume Concentration of Solids $\left.\left(\mathrm{m}^{3} \mathrm{~m}^{-3}\right)\right)$ \\
\hline$V_{t}$ & $\begin{array}{l}\text { Total Merged Volume Concentration (Volume from the LISST and } \\
\text { DFC }\left(\mathrm{m}^{3} \mathrm{~m}^{-3}\right) \text { ) }\end{array}$ \\
\hline$V_{\text {LISST }}$ & Particle Volume Concentration (from the LISST only $\left(\mathrm{m}^{3} \mathrm{~m}^{-3}\right)$ ) \\
\hline Ws & Settling Velocity $\left(\mathrm{mm} \mathrm{s}^{-1}\right.$ converted to $\left.\mathrm{m} \mathrm{s}^{-1}\right)$ \\
\hline WTS & $\begin{array}{l}\text { Water Transfer System (McLane Research Laboratories, Inc. } \\
\text { Phytoplankton Sampler) }\end{array}$ \\
\hline$\mu$ & Viscosity $\left(\mathrm{kg}(\mathrm{m} \mathrm{s})^{-1}\right)$ \\
\hline$\rho_{a}$ & Apparent Density $\left(\mathrm{kg} \mathrm{m}^{-3}\right)$ \\
\hline$\rho a_{D V C}$ & Apparent Density estimated from DVC method $\left(\mathrm{kg} \mathrm{m}^{-3}\right)$ \\
\hline$\rho a_{L D}$ & Apparent Density estimated from LD method $\left(\mathrm{kg} \mathrm{m}^{-3}\right)$ \\
\hline$\rho a_{S P M}$ & Apparent Density from observed measurements $\left(\mathrm{kg} \mathrm{m}^{-3}\right)$ \\
\hline$\rho_{e}$ & Effective Density $\left(\mathrm{kg} \mathrm{m}^{-3}\right)$ \\
\hline$\rho_{f}$ & Floc Density $\left(\mathrm{kg} \mathrm{m}^{-3}\right)$ \\
\hline$\rho_{s}$ & Component Particle Density $\left(\mathrm{kg} \mathrm{m}^{-3}\right)$ \\
\hline$\rho_{w}$ & Water Density $\left(\mathrm{kg} \mathrm{m}^{-3}\right)$ \\
\hline
\end{tabular}

Table 1: Notation and abbreviation. 


\begin{tabular}{|c|c|c|c|}
\hline Experiment & Data Collection Location & $\begin{array}{c}\text { Time of Data } \\
\text { Collection }\end{array}$ & Environment Summary \\
\hline Oasis 2007 & $\begin{array}{c}\text { Martha's Vineyard Coastal } \\
\text { Observatory 12-m offshore node, } \\
\text { Woods Hole, Massachusetts, US }\end{array}$ & Fall 2007 & $\begin{array}{c}\text { Wave-influenced } \\
\text { nearshore bottom } \\
\text { boundary layer }\end{array}$ \\
\hline Willapa & Willapa Bay, Washington, US & Summer 2009 & Mesotidal mud flat \\
\hline Oasis 2011 & $\begin{array}{c}\text { Martha's Vineyard Coastal } \\
\text { Observatory 12-m offshore node, } \\
\text { Woods Hole, Massachusetts, US }\end{array}$ & Fall 2011 & $\begin{array}{c}\text { Wave-influenced } \\
\text { nearshore bottom } \\
\text { boundary layer }\end{array}$ \\
\hline Rivet 1 & $\begin{array}{c}\text { New River Inlet, North Carolina, } \\
\text { US }\end{array}$ & Spring 2012 & River inlet \\
\hline PARR 1 & $\begin{array}{c}\text { Aquaculture Site, Bay of Fundy, } \\
\text { New Brunswick, Canada }\end{array}$ & Early Fall 2012 & $\begin{array}{c}\text { Nearshore aquaculture } \\
\text { site, macrotidal }\end{array}$ \\
\hline PARR 2 & $\begin{array}{c}\text { Aquaculture Site, Bay of Fundy, } \\
\text { New Brunswick, Canada }\end{array}$ & Late Fall 2012 & $\begin{array}{c}\text { Nearshore aquaculture } \\
\text { site, macrotidal }\end{array}$ \\
\hline Hudson & Minas Basin, Canada & Summer 2013 & Macrotidal bay \\
\hline
\end{tabular}

Table 2: Experiment summary outlining location and time of data collection in data collection. Data from Oasis 2007, Willapa, and merged data from Oasis 2011 were archived data. The remaining data sets were processed by the author. 


\begin{tabular}{|c|c|c|c|}
\hline Experiment & Deployment Type & LISST Type & $\begin{array}{c}\text { Number of Merged } \\
\text { Size Distributions }\end{array}$ \\
\hline Oasis 2007 & Stationary & Type B & 5725 \\
\hline Willapa & Stationary & Type B & 1399 \\
\hline Oasis 2011 & Stationary & Type C & 3814 \\
\hline Rivet 1 & Cast & Type C & 1176 \\
\hline PARR 1 & Stationary & $\begin{array}{c}\text { Type B (Deployment } \\
\text { 2) and Type C } \\
\text { (Deployment 1 and 3) }\end{array}$ & $\begin{array}{c}\text { Type B: } 1074 \\
\text { Type C: } 2859\end{array}$ \\
\hline PARR 2 & Stationary & Type B & 4339 \\
\hline Hudson & Stationary & Type B & 1799 \\
\hline
\end{tabular}

Table 3: Summary table of data collected from instruments used in the LD method. Summary includes: the deployment type, the LISST type that was used, and the total number of merged size distributions.

\begin{tabular}{|c|c|c|c|}
\hline Experiment & $\begin{array}{c}\text { Number of SPM Data } \\
\text { Points }\end{array}$ & $\begin{array}{c}\text { Median SPM } \\
\left(\mathbf{m g ~ L}^{-\mathbf{1}}\right)\end{array}$ & $\begin{array}{c}\text { Median Apparent } \\
\text { Density } \\
\left(\mathbf{k g ~ m}^{-3} \mathbf{)}\right.\end{array}$ \\
\hline Oasis 2007 & 121 & 2.74 & 240 \\
\hline Oasis 2011 & 114 & 5.60 & 24 \\
\hline PARR 1 & 48 & 6.25 & $\begin{array}{c}\text { Type B: } 240 \\
\text { Type C: } 360\end{array}$ \\
\hline PARR 2 & 70 & 3.97 & 190 \\
\hline Hudson & 24 & 2.67 & 240 \\
\hline
\end{tabular}

Table 4: Summary table of estimates of apparent density based on measured SPM. 


\begin{tabular}{|c|c|c|c|c|c|}
\hline Experiment & $\begin{array}{c}\text { Video } \\
\text { Clips }\end{array}$ & $\begin{array}{l}\text { Particles } \\
\text { Tracked }\end{array}$ & $\begin{array}{l}\text { Median } \\
\text { Settling } \\
\text { Velocity } \\
\left(\mathrm{mm} \mathrm{s}^{-1}\right)\end{array}$ & $\begin{array}{c}\text { Median } \\
\text { Particle } \\
\text { Diameter } \\
(\mu \mathrm{m})\end{array}$ & $\begin{array}{c}\text { Median } \\
\text { Apparent } \\
\text { Density } \\
\left(\mathrm{kg} \mathrm{m}^{-3}\right)\end{array}$ \\
\hline Oasis 2007 & 315 & 7606 & 1.06 & 400 & 27 \\
\hline Willapa & 93 & 3398 & 1.13 & 320 & 40 \\
\hline Oasis 2011 & 104 & 2242 & 0.82 & 370 & 26 \\
\hline Rivet 1 & 52 & 777 & 0.88 & 310 & 43 \\
\hline PARR 1 & 195 & 3748 & 0.81 & 320 & 29 \\
\hline PARR 2 & 114 & 2565 & 0.89 & 300 & 33 \\
\hline Hudson & 73 & 1587 & 1.10 & 310 & 45 \\
\hline
\end{tabular}

Table 5: Summary table of DVC data. Experiments are in chronological order.

\begin{tabular}{|c|c|c|c|}
\hline Experiment & $\begin{array}{c}\text { Number of Merged } \\
\text { Data Points }\end{array}$ & $\begin{array}{l}\text { Median D50 } \\
(\mu \mathrm{m})\end{array}$ & $\begin{array}{c}\text { Median Apparent } \\
\text { Density } \\
\left(\mathrm{kg} \mathrm{m}^{-3}\right)\end{array}$ \\
\hline Oasis 2007 & 5725 & 270 & 100 \\
\hline Willapa & 1399 & 140 & 65 \\
\hline Oasis 2011 & 3814 & 270 & 15 \\
\hline Rivet 1 & 1176 & 160 & 44 \\
\hline PARR 1 & $\begin{array}{l}\text { Type B: } 1074 \\
\text { Type C: } 2859\end{array}$ & $\begin{array}{l}\text { Type B: } 140 \\
\text { Type C: } 140\end{array}$ & $\begin{array}{l}\text { Type B: } 32 \\
\text { Type C: } 91\end{array}$ \\
\hline PARR 2 & 4339 & 290 & 70 \\
\hline Hudson & 1799 & 300 & 29 \\
\hline
\end{tabular}

Table 6: Summary table of merged data used in the LD method. 


\begin{tabular}{|c|c|c|c|}
\hline Experiment & $\begin{array}{c}\text { Number of LISST Data } \\
\text { Points }\end{array}$ & $\begin{array}{c}\text { Median D50 } \\
(\boldsymbol{\mu m})\end{array}$ & $\begin{array}{c}\text { Median } \mathbf{C}_{\mathbf{p}}: V_{\text {LISST }} \\
\left(\mathbf{k g ~ m}^{-\mathbf{3}} \mathbf{)}\right.\end{array}$ \\
\hline Oasis 2007 & 5725 & 30 & $\mathbf{2 2 0}$ \\
\hline Oasis 2011 & 3814 & 340 & 50 \\
\hline PARR 1 & Type B: 1074 & Type B: 80 & Type B: 60 \\
Type C: 2859 & Type C: 350 & Type C: 60 \\
\hline PARR 2 & 4339 & 90 & 120 \\
\hline Hudson & 1796 & 120 & 40 \\
\hline
\end{tabular}

Table 7: Summary table of the LISST data used in the $c_{p}: V_{\text {LISST }}$ comparison with the SPM method.

\begin{tabular}{|c|c|c|c|}
\hline Method Comparison & $\begin{array}{c}\text { Number of data } \\
\text { points }\end{array}$ & $\begin{array}{c}\text { Correlation } \\
\text { Coefficient } \\
(\mathbf{r})\end{array}$ & p Value \\
\hline LD vs DVC & 1116 & -0.04 & 0.28 \\
\hline LD vs SPM & 425 & 0.51 & 0 \\
\hline C $_{p}: V_{\text {LISST VS SPM }}$ & 425 & 0.32 & 0 \\
\hline
\end{tabular}

Table 8: Data table of the results from the correlation analysis using Spearman's rho for method comparisons. 
Figure 1: Apparent density estimated with the DVC method and the LD method on logarithmic scales. The $p$ value of 0.28 is significantly greater than 0.05 , which indicates that there is not a correlation between the two methods. Symbols represent the following: plus signs (Oasis 2007), downward-pointing triangles (Willapa), shaded circles (Oasis 2011), open circles (Rivet), right-pointing triangles (Parr 1), crosses (Parr 2), and diamonds (Hudson).

Figure 2: Apparent density estimated with the SPM method and the LD method in logarithmic scale. The slope of the Type II regression is equal to 1.05, with 95\% confidence intervals of 0.95 and 1.16, which implies that these two estimates of apparent density are not significantly different from a linear relationship. See Figure 1 for symbol definitions. Data sets that do not have SPM measurements are not shown.

Figure 3: Apparent density estimated with the SPM method and $c_{p}: V_{\text {LISST }}$ in logarithmic scale. The slope of the Type II regression is equal to 0.74 , with $95 \%$ confidence intervals of 0.64 and 0.84 , which implies that although these methods are correlated, the relationship is not linear. See Figure 1 for symbol definitions. Data sets that do not have SPM measurements are not shown.

Figure 4: Median diameter (D50) from LD method volume concentrations against apparent density estimates from both the DVC method (shaded circles) and the LD method (open circles) from the Parr 1 data set. As the median diameter decreases in the LD method, there is a resulting increase in apparent density. Conversely, the apparent densities for the DVC method are relatively constant, regardless of the median diameter from the volume concentrations.

Figure 5: Volume concentrations from the LISST (V $V_{\text {LISST }}$ ) compared with volume concentrations from the merged data $\left(V_{t}\right)$ for all data sets. The relationship between the two volume concentrations is linear at lower volume concentrations. At larger merged volume concentrations, however, $\mathrm{V}_{\text {LISST, }}$ values increase more slowly with increases in $\mathrm{V}_{\mathrm{t}}$ values, likely because the LISST does not measure out-of-range, larger flocs accurately.

Figure 6: Time series analysis for Oasis 2007. The top panel contains time series of shear velocity in grey $\left(\mathrm{cm} \mathrm{s}^{-1}\right)$ and beam attenuation in black $\left(c_{p}, \mathrm{~m}^{-1}\right)$. The middle panel contains LD density in grey $\left(\mathrm{kg} \mathrm{m}^{-3}\right)$ and the SPM method densities labeled with crosses $\left(\mathrm{kg} \mathrm{m}^{-3}\right)$. The bottom panel contains $\mathrm{C}_{\mathrm{p}}: \mathrm{V}_{\text {LISST }}\left(\mathrm{kg} \mathrm{m}^{-3}\right)$. 


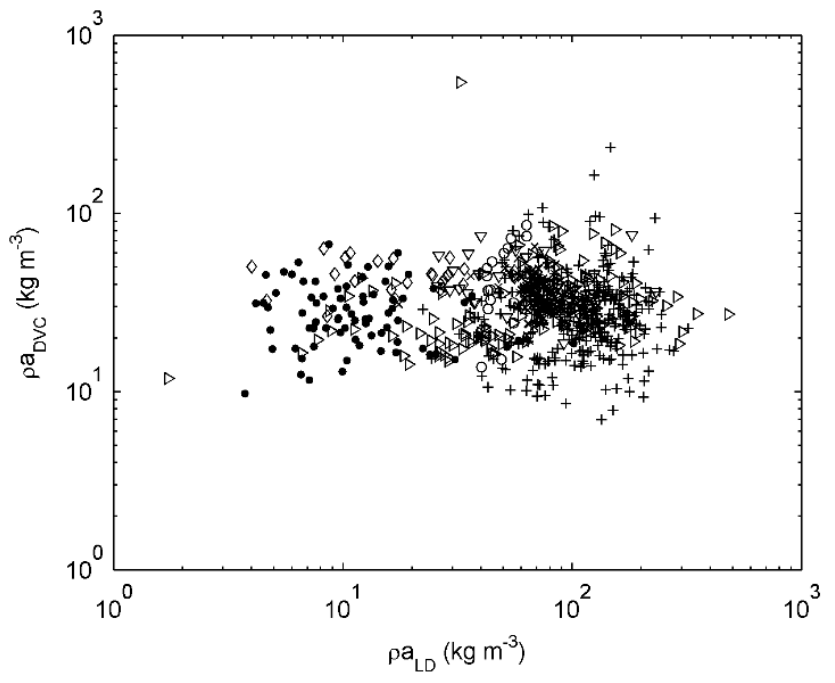




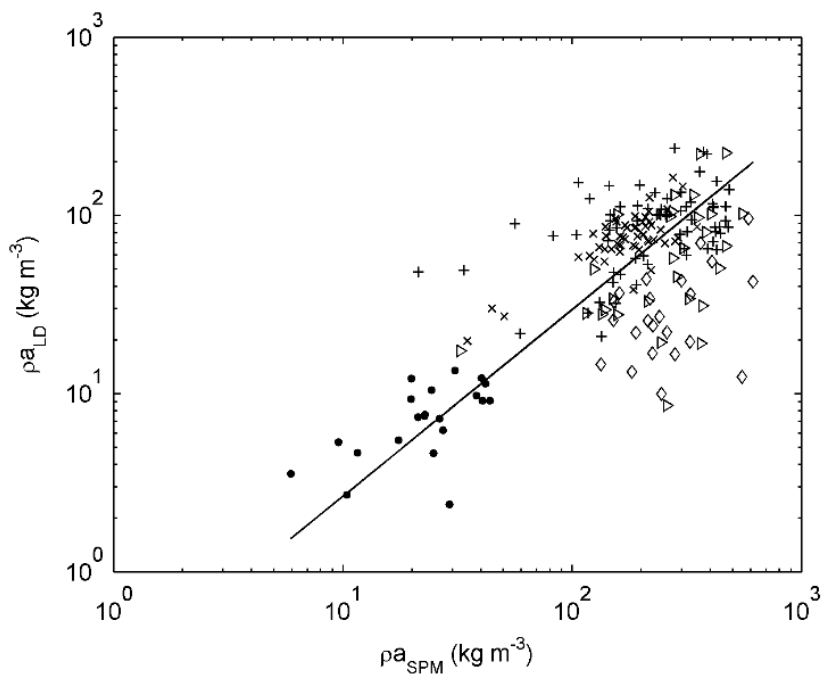




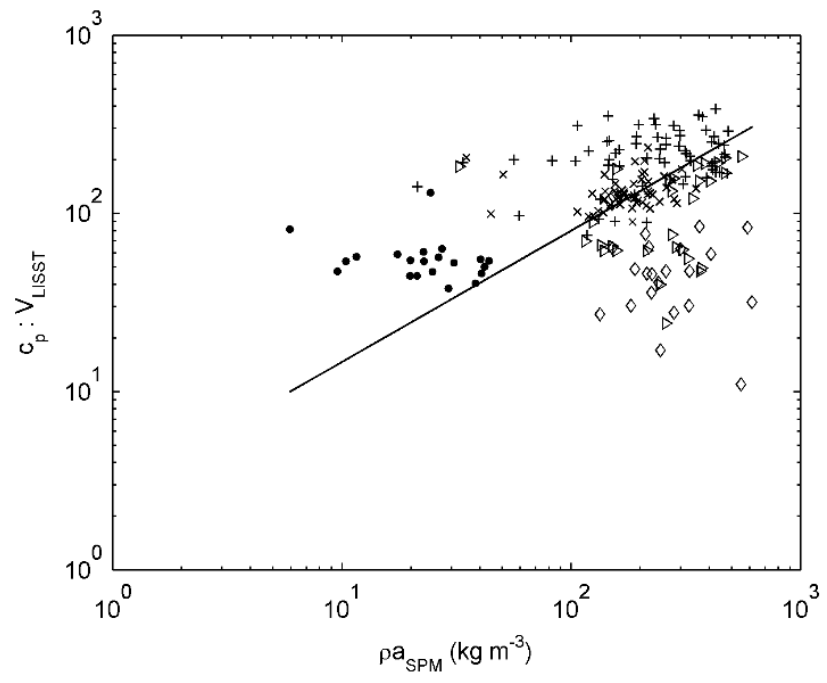




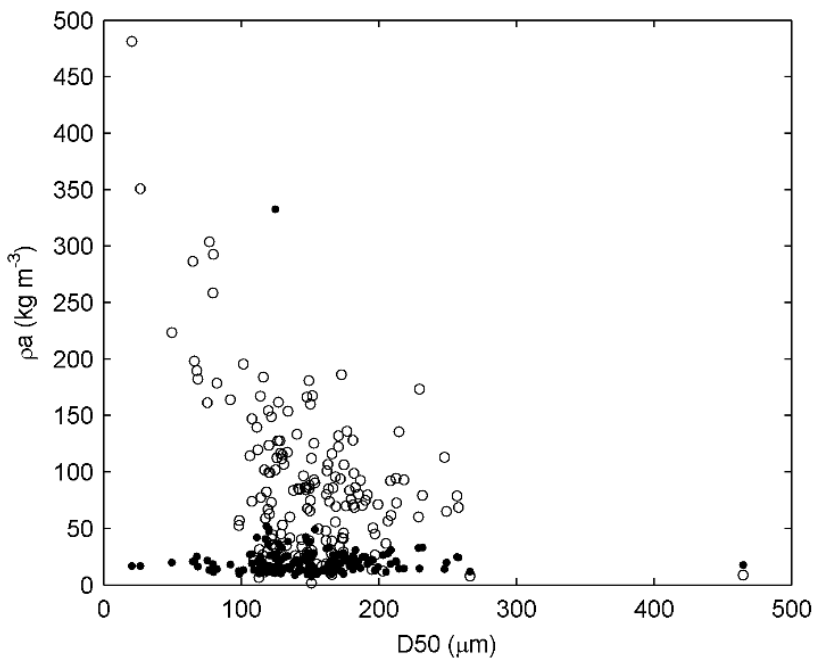




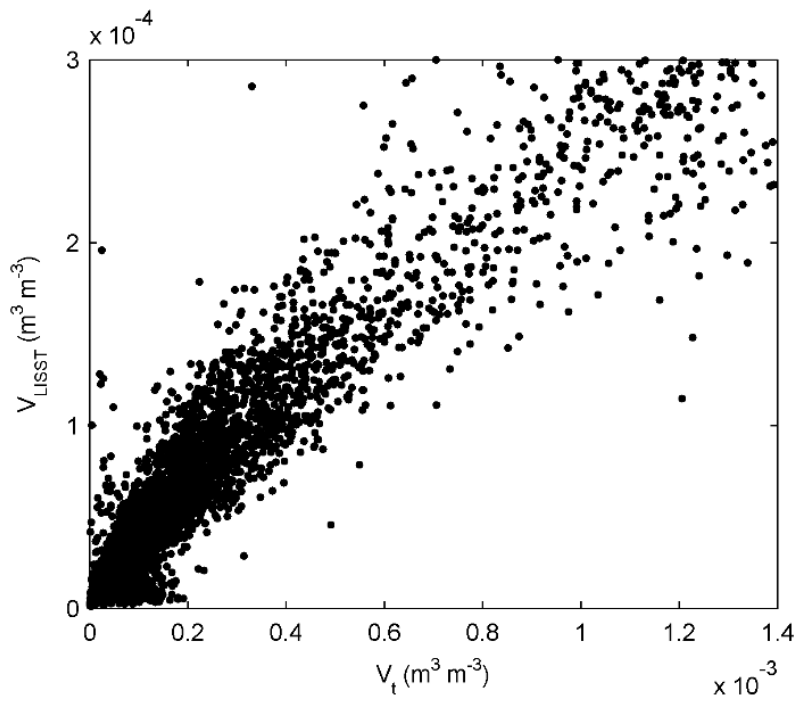



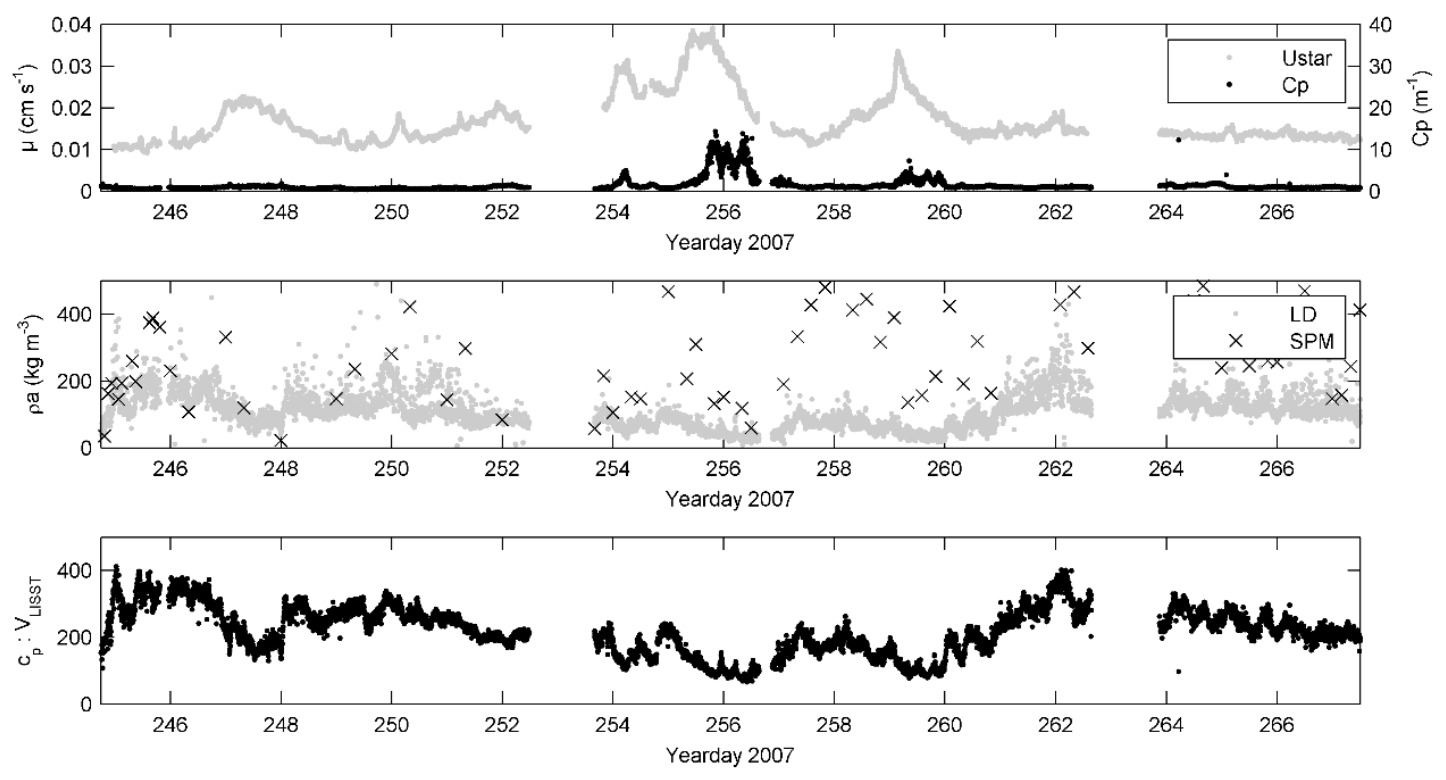